\title{
CSR Image Construction of Chinese Construction Enterprises in Africa Based on Data Mining and Corpus Analysis
}

\author{
Yaoping Zhong, ${ }^{1,2}$ Wenzhong Zhu $\mathbb{D}^{3},{ }^{3}$ and Yingying Zhou $\mathbb{D}^{3}$ \\ ${ }^{1}$ School of English for International Business, Guangdong University of Foreign Studies, Guangzhou 510420, China \\ ${ }^{2}$ College of Foreign Studies, Guangxi Normal University, Guilin 541006, China \\ ${ }^{3}$ School of Business, Guangdong University of Foreign Studies, Guangzhou 510006, China \\ Correspondence should be addressed to Wenzhong Zhu; wenzhongzhu2020@163.com
}

Received 3 May 2020; Accepted 16 June 2020; Published 15 July 2020

Guest Editor: Shianghau Wu

Copyright (c) 2020 Yaoping Zhong et al. This is an open access article distributed under the Creative Commons Attribution License, which permits unrestricted use, distribution, and reproduction in any medium, provided the original work is properly cited.

\begin{abstract}
Since there is negative coverage of some western media on the business activities of Chinese overseas enterprises, which has adverse impact on the image of Chinese enterprises and even the national image of China, this study aims to detect the corporate social responsibility image (hereafter CSR image) of Chinese construction enterprises in Africa (hereafter CCEA) through analyzing the coverage of Financial Times (hereafter FT) from the UK and The Wall Street Journal (hereafter WSJ) from the US and dig up the motives behind their coverage. Octopus is first applied to mine and collect the reports data on CCEA from 2011 to 2019 by the two media. Two small corpora including the reports are then built. NVivo is next used to do the statistical analysis and clustering analysis of the keywords in two corpora as a whole and AntConc is finally utilized to do the statistics of high-frequency evaluative adjectives and nouns modified by evaluative adjectives as well as the concordance of the low-frequency words but closely relevant to corporate social responsibility (hereafter CSR) in two corpora, respectively. The results of the detailed analyses of the keywords are combined to unveil the CSR image of CCEA, which is followed by a discussion about the motives behind the coverage and finally some suggestions are put forward to improve the CSR image of CCEA. Theoretically, the present study promotes the interaction among data science, management, communications, and linguistics; practically it offers some advice to CCEA to elevate their CSR image.
\end{abstract}

\section{Introduction}

Since the Belt and Road Initiative (hereafter BRI) was put forward in 2013, China has been broadening its cooperation network. As of the end of January 2020, China has signed up to 200 BRI cooperation documents with 138 countries and 30 international organizations [1]. The African continent, with great development potential, is an important destination and foothold for China to push the BRI towards the west. By the end of January 2020, a total of 44 African countries have signed the BRI cooperation documents with China [1]. The construction advanced by BRI brings unprecedented opportunities as well as huge challenges to China-Africa cooperation. China's investment in Africa is mainly concentrated in the construction, mining, manufacturing, finance, and technology services.
Among them, infrastructure construction in the construction industry is one of the highlights [2]. Thus it can be seen that China's overseas contracted project is one of the main directions of investment in Africa.

However, the construction industry is rather sensitive to the issues like labor safety, production cost, and environmental protection. With more Chinese enterprises investing and trading in Africa, such negative remarks as "neocolonialism" and "resource predator" spread in all kinds of news reports, which prevail in the west and even in some African countries. A survey on "Africans' Perceptions of Chinese Business in Africa" displays that $58 \%$ of 1,056 Africans from 15 African countries held a negative view that Chinese enterprises did not have a good reputation in their countries [3]. The root cause of this negative speech is that China-Africa 
cooperation is becoming more pragmatic in the new century, while the direct cause is some Chinese enterprises' inadequacy or failure of fulfilling their social responsibilities in Africa. As the representative entities of operating abroad, Chinese enterprises are not only economic actors, but also "social responsibility bearers." CSR has a positive effect on corporate image and on customer citizenship behavior [4]; therefore, it is urgent for CCEA to polish their CSR image.

Although researches on CSR drivers or influence factors [5-8] and the relations between CSR and corporate performance [9-12] are prominently offered, only a few studies concentrate on the impact of media coverage on CSR [13-15] and CSR activities or themes of construction industry [16-18] and it is even rare to see the studies on CSR image of Chinese overseas construction enterprises. Therefore, the current study aims to probe into the CSR image of CCEA through answering the following questions based on the analyses of the news reports of two mainstream media, namely, Financial Times from UK and The Wall Street Journal from the US.

(1) What is the CSR image of Chinese construction enterprises in Africa under the coverage of Financial Times and The Wall Street Journal?

(2) What are the motives behind the two media's coverage of such an image?

(3) How can Chinese construction enterprises in Africa improve their CSR image?

\section{Literature Review}

2.1. Definition of CSR. "Social Responsibilities of the Businessman" written by Howard R. Bowen was published in 1953, which marks the beginning of the study of CSR in modern literature. In his book, Bowen [19] defined social responsibility as "the obligations and responsibilities of businessmen, that is, businessmen have the obligation to determine policies, make decisions, and take actions according to the goals and values of the society." Even though businesses are mainly driven by profits, CSR is not just about economic responsibilities of the enterprises. Some scholars have discussed the dimensions of CSR. Carroll $[20,21]$ conceptualized the CSR model by four responsibilities: economic responsibility, legal responsibility, ethical responsibility, and philanthropic responsibility. Dahlsrud [22] identified five major dimensions of CSR based on the analysis of 37 definitions of CSR since 1980, namely, economic dimension, social dimension, environmental dimension, stakeholder dimension, and voluntariness dimension.

Research on CSR in China starts late compared with the west. In China CSR movement was brought in on a large scale in 1990s, especially since China implemented the strategies of "Two Resources and Two Markets" and "Going Global," and there has been a growing demand for enterprises to fulfill their social responsibilities internationally [23]. Liu [24] proposed a broad sense and a narrow sense regarding CSR. The broad view holds that CSR is the responsibility of enterprises to all stakeholders, including shareholders. The narrow sense is divided into two views. One refers to enterprises' pursuit of profit maximization and the other points to the responsibility to all stakeholders excluding shareholders. The connotation of CSR has become increasingly rich with the wide spread of the concept in China and the enterprises' deepening understanding of it. The Chinese government holds that companies should fulfill their social responsibilities and abide by the relevant laws, regulations, and business ethics. To be more specific, while pursuing economic interests, an enterprise is responsible for stakeholders, employees, consumers, suppliers, communities, and other interested parties as well as environmental protection.

There are also some definitions of CSR posed by international organizations. Yang [25] discussed several definitions of CSR in the summary of International Symposium on "Corporate Social Responsibility and Development in Africa." For example European Commission points out that "CSR is a concept in which a company voluntarily decides to contribute to a better society and a cleaner environment as well as a concept of an interactive relationship between a company and its stakeholders on a voluntary basis by combining its operations with society and the environment." According to the World Bank, CSR is the commitment and obligation of enterprises to contribute to sustainable economic development and promote their own and society's development by working together with their employees and their families, local communities, and even all the people of the society. World Business Council for Sustainable Development defines CSR as the continuous commitment of enterprises to make contributions to economic development and operate by law while improving the life quality of workers and their families, local communities, and the majority of the society. Business for Social Responsibility holds that CSR is the business activities conducted on the basis of meeting or exceeding the public expectations on morality, law, and commerce. Wu et al. [26] proposed a definition in their paper based on an overview of CSR research development; that is, CSR means an enterprise is responsible for all of its stakeholders in its operations and activities to balance the needs of stakeholders and the profits of the company by considering the impact of their operations and activities on labor, the environment, communities, customers, and even their competitors when making decisions.

Even though there are different versions of the definition of CSR, most of the versions share great commonalities. To conclude, CSR in this study refers to the responsibility and obligation that enterprises should fulfill to such stakeholders as shareholders, employees, consumers, and their communities during the process of pursuing economic interests.

2.2. Definition of CSR Image. CSR image is closely relevant to both CSR and corporate image. Corporate image is the result of an aggregate process by which the public compares and contrasts the various attributes of firms [27]. To be more specific, corporate image refers to the impression and evaluation of the public and employees on an enterprise, 
which consists of product image, media image, and the like, while CSR image is less complex than corporate image. Liu [24] defined CSR image as people's impression of an enterprise's attitude and behavior towards stakeholders excluding shareholders and a wide range of social issues, or people's attitude and evaluation of the enterprise based on its CSR concept and behavior. Thus it can be said that CSR image is the direct reflection of CSR behavior, which is formed on the basis of the social attributes of the enterprise and the social responsibility it undertakes.

2.3. Significance of CSR. At the early beginning, many enterprises regarded CSR as charitable activities like donation, and even a burden for the enterprises which still struggle to survive. Fortunately, both western and Chinese enterprises have a deeper understanding of CSR nowadays and realize its importance after their experience of the four-stage development, namely, start, development, maturity, and steady development or suffering of crisis. Externally, to ensure the healthy and orderly operation, an enterprise must respect and satisfy the interests of stakeholders and establish a harmonious relationship with them, which is conducive to maintaining and even expanding its profits. Internally, fulfilling CSR benefits the enterprise in improving employees' sense of mission and satisfaction, enhancing an enterprise's innovation ability, building a positive corporate culture, and strengthening its cohesion.

In the era of economic globalization, fulfilling CSR is not only beneficial to economic development and social progress, but also helpful to the long-term development of enterprises, for they can promote and maintain economic growth, reduce poverty, and create prosperity by providing investment, technology, jobs, and training of labor skills. When pursuing economic benefits, enterprises produce products and services that meet the needs of the society, thus promoting the growth of the economy [25]. More researchers argue the benefits of fulfilling CSR to the elevation of corporate image [24, 28]. Liu [24] pointed out that a positive CSR image is a shortcut for enterprises to obtain strategic advantage in the information age. As to the promotion of China's soft power in Africa, Song [28] stated that it is of strategic significance for Chinese enterprises in Africa to strengthen CSR building under the background of the implementation of "Going Global" strategy and China's imbalance development of soft and hard power in Africa.

2.4. Research on CSR of Chinese Enterprises in Africa. The western media have reported much on the economic activities of Chinese enterprises in Africa, but few western scholars pay attention to the CSR implementation of Chinese enterprises in Africa. On the contrary, Chinese scholars have been keeping their enthusiasm in this field. Some of them agree that fulfilling CSR is of great significance for Chinese enterprises to operate in Africa $[29,30]$. Some Chinese enterprises in Africa, however, do not attach enough importance to CSR, thus giving chances to the western countries to smear Chinese overseas companies, which seriously damages the image of Chinese enterprises in
Africa and even the image of China [28, 30]. Fortunately, more and more Chinese researchers have realized the poor CSR performance of some Chinese enterprises in Africa and proposed solutions to the problems after analyzing the causes behind this phenomenon [31-34]. In recent years, some researchers have conducted in-depth research on the understanding and implementation of CSR in China through case analysis and field investigation $[23,29,31,35]$, and their findings reveal that most firms have shouldered their responsibilities, with the big state-owned enterprises performing better than the small private ones [36]. One typical example is illustrated by Feng's [37] study which analyzed the Mombasa-Nairobi Standard Gauge Railway Project in Kenya constructed by the China Road and Bridge Corporation.

Some limitations of the abovementioned studies should not be neglected. In terms of research methods, most of the abovementioned studies adopt qualitative research methods, which are mostly limited to summary of experience or lessons. Case study is widely used in these qualitative researches and although the results are persuasive, the generalization of their conclusions is limited by the number of samples. As to the source of data, second-hand data is collected in most of the researches, and only a minority of the data are collected through face-to-face interviews and field investigation. News data are easy to collect in great quantity, yet only few studies are conducted to explore CSR through the analysis of news reports. Thus the present study will first apply Octopus to collect the news data related to CCEA from FT and WSJ, then NVivo to do the clustering analysis [38] to classify the keywords of the news reports, and next AntConc to do the word frequency statistics. This is an interdisciplinary study involving data science, management, communications, and linguistics, which innovates the research perspectives and methods of CSR study.

\section{Methodology}

3.1. Sample and Data Collection. Although social media plays an increasingly important role in people's life, wordof-mouth still plays a large part in people's communication and it is often beyond enterprises' ability to control the dissemination of news through this nonmass media. Therefore, many enterprises still prioritize mass media to promote their corporate image [39]. In this study, we choose FT and WSJ as two representative mainstream media based on their huge influence in providing business news. FT is a world famous international financial media. As of October 2019 , its print circulation and digital circulation reach 168,958 and 740,000 , respectively [40]. WSJ is a comprehensive newspaper featured by financial reports, focusing on financial and business coverage and has a broad influence on the international community. As of August 2019, its daily circulation reaches 2,834,000 [41].

Since we focus on the CSR image portrayed by the western media in this study, news data is collected from the ProQuest ABI/INFORM business information database which was released by ProQuest, an American company, 40 years ago. Guangdong University of Foreign Studies where 
the authors study or work has purchased this database as part of its library resources. The database has long been a gold standard for business information storage, providing a wealth of information resources in economics, management, business, and related fields. Africa has witnessed some progress in understanding CSR since 2011, which pushes CSR construction into a consensus stage [42]. In view of this, we set the period of news collection from January 1, 2011, to December 31, 2019, a total of nine years. The data is collected in four steps, which is illustrated as follows.

Step 1: the publication type was set to newspaper, the document type to news, and the language to English. Keyword search was conducted by entering Chin* (including China and Chinese) construction compan* (including company and companies) and Afric* (including Africa and African). 3813 news reports were obtained after the retrieval.

Step 2: only FT and WSJ were focused, and 585 news reports from the former and 937 news reports from the latter were gained, respectively, after the screening.

Step 3: the websites of the database were mined to collect the screened news reports by Octopus and saved in xls format, with the titles, sources, and content of the news reports remained only.

Step 4: 19 news reports from the FT and 14 news reports from WSJ were further chosen for the current study after two researchers' browsing of the titles and content of the news reports and their consensus on the selected reports. Finally the news reports in xls format were transferred into txt format for the convenience of subsequent processing of the data.

3.2. Data Analysis. Clustering analysis is conducted to classify the keywords of the news reports in this study. It is a technique for analyzing statistical data and is widely used in many fields, including machine learning, data mining, pattern recognition, image analysis, and biological information. Clustering is a static classification of similar objects into different groups or more subsets so that each member in the same subset shares some similar properties, such as shorter spatial distance in a coordinate system. This analytical method is now widely used in public opinion research and enterprise perfection.

NVivo is utilized to first retrieve the 33 news reports from the two media, then extract the information of the news reports to count the word frequencies, and finally select the first $30 \%$ of the keywords as high-frequency ones which are related to the topics about CSR of CCEA. These high-frequency keywords are presented in a table in terms of serial number, content, frequency, percentage, and cumulative percentage. The software is also used to generate a word cloud and do the clustering analysis. We interpret the clusters to detect the relationship between the high-frequency keywords and reveal the structure of these research focuses.

As a complement to the clustering analysis, the corpus tool AntConc is first used to conduct word frequency of the
33 news reports and pick out the top 15 high-frequency lemmas to reveal which words the two media use to report CCEA. Then, we analyze the news headlines to see what events the two media focus on. Next, we count the evaluative adjectives and nouns modified by evaluative adjectives which are relevant to CSR performance of these Chinese companies to elicit the overall CSR image of CCEA.

\section{Results and Discussion}

4.1. Statistics of Keywords. In this study a total of 3,766 keywords are extracted, the first $30 \%$ of which are processed to generate a word cloud (see Figure 1). The bigger the word in the word cloud, the higher frequency it appears in the coverage. It is clear to see that the FT and WSJ mainly focus on Chinese companies' infrastructure construction, projects, and investments in Africa, which is supported by the Chinese government.

More details of the coverage by the two media can be revealed in terms of the frequency and cumulative percentage of the first 30\% high-frequency keywords which are the focus of the present study. We are able to reveal the themes of the coverage of the two media regarding CCEA by referring to these high-frequency keywords. It can be seen from Table 1 that there are 42 high-frequency keywords in the coverage, with a total frequency of 3844 times, accounting for $29.82 \%$ of the total.

4.2. Clustering Analysis of Keywords. Keywords embody the topics of a news report, so clustering analysis of the 42 keywords is conducted to highlight the focuses of the coverage of CCEA as well as the consistency of the topics. Figure 2 demonstrates the tree graph of high-frequency keywords, in which the vertical distance within each cluster at the horizontal level means the average distance between two words. The distance indicates their intimate relations, so the shorter the distance, the closer their connotation, which suggests a higher frequency of their concurrence in the same report and in turn reflects greater consistence of the topic. Figure 2 demonstrates that there are four clusters which refer to four CSR focuses on CCEA. The four coverage hotspots include (1) Chinese state-owned construction enterprises' investment in infrastructure and trading with African countries; (2) China's economic assistance to Africa by financing projects and China's business activities involving military action; (3) China's investment in power plants construction and officials' involvement in construction activities; and (4) China's international construction companies' contribution to the world development.

4.3. Statistics of High-Frequency Lemmas. To seek more evidence for the revelation of the themes of the coverage about CCEA, high-frequency content words like nouns and verbs are counted (see Table 2 ). The statistics only focus on lemmas, which are the words derived from the same stem, so that different word forms of a stem can be included in the frequency of the same lemma. Different from the frequency statistics in Table 1 of section 4.1, the frequency statistics in 


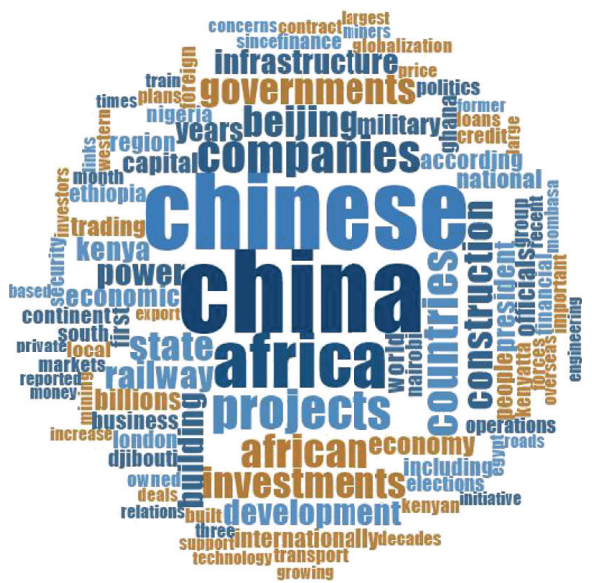

Figure 1: The word cloud of the news reports of FT and WSJ.

TABLE 1: High-frequency keywords in the news reports of FT and WSJ.

\begin{tabular}{|c|c|c|c|}
\hline No. & Words & Frequency & Weighted percentage (\%) \\
\hline 1 & china & 357 & 1.66 \\
\hline 2 & chinese & 327 & 1.52 \\
\hline 3 & africa & 231 & 1.08 \\
\hline 4 & projects & 156 & 0.73 \\
\hline 5 & companies & 144 & 0.67 \\
\hline 6 & countries & 135 & 0.63 \\
\hline 7 & african & 124 & 0.58 \\
\hline 8 & investments & 111 & 0.52 \\
\hline 9 & beijing & 112 & 0.52 \\
\hline 10 & state & 112 & 0.52 \\
\hline 11 & governments & 110 & 0.51 \\
\hline 12 & construction & 108 & 0.5 \\
\hline 13 & railway & 95 & 0.44 \\
\hline 14 & building & 87 & 0.41 \\
\hline 15 & power & 89 & 0.41 \\
\hline 16 & development & 85 & 0.4 \\
\hline 17 & infrastructure & 81 & 0.38 \\
\hline 18 & kenya & 74 & 0.34 \\
\hline 19 & years & 71 & 0.33 \\
\hline 20 & economic & 66 & 0.31 \\
\hline 21 & economy & 67 & 0.31 \\
\hline 22 & president & 65 & 0.3 \\
\hline 23 & billions & 65 & 0.3 \\
\hline 24 & capital & 60 & 0.28 \\
\hline 25 & world & 58 & 0.27 \\
\hline 26 & officials & 59 & 0.27 \\
\hline 27 & military & 59 & 0.27 \\
\hline 28 & trading & 55 & 0.26 \\
\hline 29 & national & 55 & 0.26 \\
\hline 30 & region & 53 & 0.25 \\
\hline 31 & according & 53 & 0.25 \\
\hline 32 & internationally & 51 & 0.24 \\
\hline 33 & first & 51 & 0.24 \\
\hline 34 & people & 50 & 0.23 \\
\hline 35 & including & 47 & 0.22 \\
\hline 36 & business & 48 & 0.22 \\
\hline 37 & nigeria & 45 & 0.21 \\
\hline 38 & continent & 45 & 0.21 \\
\hline 39 & financial & 45 & 0.21 \\
\hline 40 & london & 46 & 0.21 \\
\hline 41 & ghana & 46 & 0.21 \\
\hline 42 & ethiopia & 46 & 0.21 \\
\hline
\end{tabular}

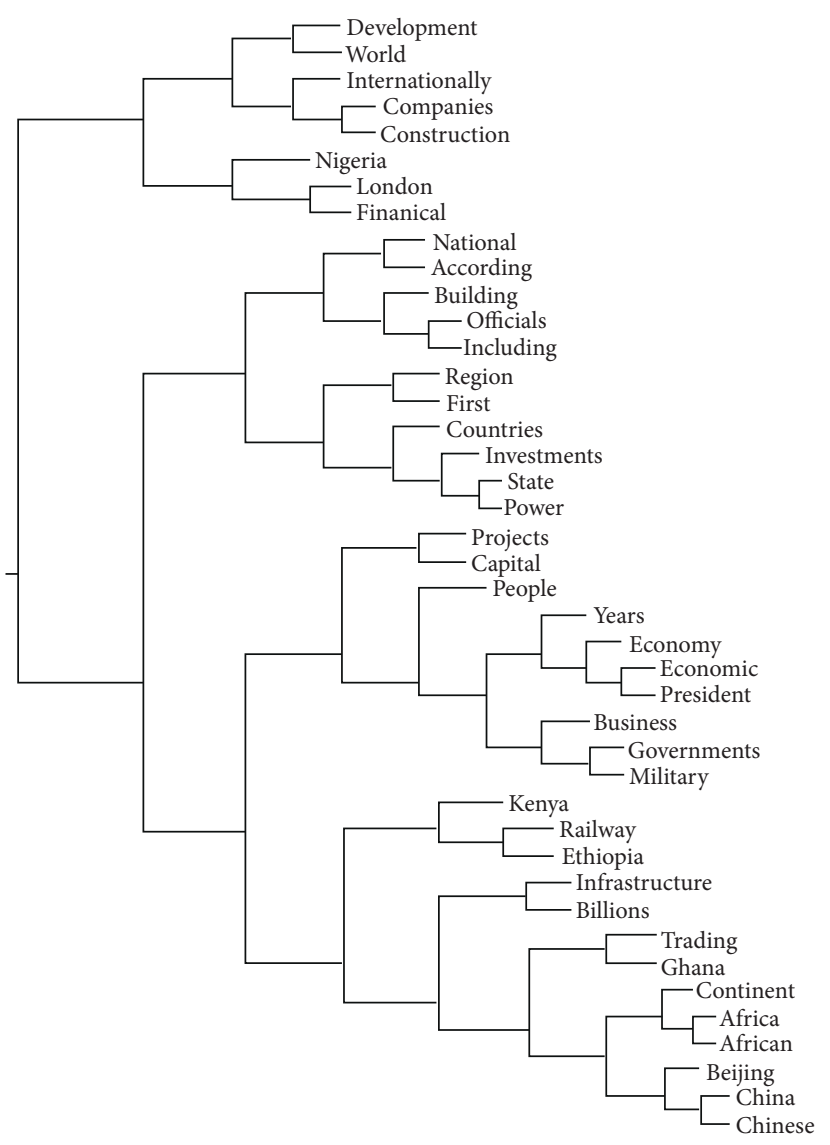

Figure 2: The tree graph of high-frequency keywords in the news reports of FT and WSJ.

Table 2 provides respective details of the focuses of FT and WSJ. We can see that the lemmas like China, Chinese, Africa, African, project, and Beijing appear in the two corpora, only with different frequencies. In addition, the lemma state appears in FT and government appears in WSJ, which indicates that the activities of CCEA are supported by the Chinese government. In general, the two media are focused on the projects carried out by Chinese construction enterprises, with the difference lying in FT concerning railway construction while WSJ linking China's military activities to infrastructure construction and highlighting the economic scale of these projects.

4.4. Headline Analysis. The headline represents the main idea of a news report, so headlines of the news reports of the two media are compared below to dig more details about the themes of their coverage. It is clear to see from Table 3 that the headlines of FT news are obviously shorter than those of WSJ. As to the content of the headlines, FT uses relatively objective titles which mainly focus on Chinese companies helping African countries build railways and roads, while WSJ tends to use negative titles. For example, the headline of article 3 from WSJ argues that most African countries are caught in a debt trap designed by China, and China's growing economic and military influence on the continent has raised concerns in the west. 
TABLE 2: The top 15 high-frequency lemmas in the news reports of FT and WSJ.

\begin{tabular}{|c|c|c|c|c|}
\hline & FT corpus & Frequency & WSJ corpus & Frequency \\
\hline 1 & China & 204 & China & 153 \\
\hline 2 & Chinese & 197 & say & 153 \\
\hline 3 & say & 156 & Chinese & 131 \\
\hline 4 & Africa & 137 & Africa & 94 \\
\hline 5 & company & 99 & year & 85 \\
\hline 6 & project & 75 & new & 81 \\
\hline 7 & railway & 75 & project & 80 \\
\hline 8 & African & 74 & country & 68 \\
\hline 9 & more & 72 & government & 64 \\
\hline 10 & state & 72 & billion & 59 \\
\hline 11 & construction & 69 & military & 57 \\
\hline 12 & year & 68 & economy & 55 \\
\hline 13 & country & 67 & more & 52 \\
\hline 14 & power & 65 & African & 50 \\
\hline 15 & Beijing & 64 & Beijing & 48 \\
\hline
\end{tabular}

TABLE 3: Statistics of headlines of the new reports of FT and WSJ.

\begin{tabular}{|c|c|c|}
\hline & FT corpus & WSJ corpus \\
\hline 1 & Chinese builders target contracts in EU and US & $\begin{array}{l}\text { Soft power: China backs Egypt's new } \$ 45 \text { billion. Capital; deal to build new capital } \\
\text { near Cairo is part of Beijing's plans to boost business in emerging markets }\end{array}$ \\
\hline 2 & $\begin{array}{c}\text { Construction companies stage second act } \\
\text { overseas }\end{array}$ & $\begin{array}{l}\text { Violence imperils Kenya port project; land disputes, terrorism threaten plan to turn } \\
\text { Coastal Region into economic hub }\end{array}$ \\
\hline 3 & China's plan to connect the world & $\begin{array}{l}\text { More of Africa finds itself in China's debt; Beijing's widening economic and military } \\
\text { footprint on continent raises concerns; president. Xi Jinping secures host of deals on } \\
\text { weeklong visit }\end{array}$ \\
\hline 4 & $\begin{array}{l}\text { Chinese investors herald second golden age of } \\
\text { east Africa rail building }\end{array}$ & $\begin{array}{l}\text { After winning Re-Election, Kenya's president faces economic, social challenges; } \\
\text { Uhuru Kenyatta's tasks: keeping economy ticking, cutting debt, and uniting a nation } \\
\text { divided along tribal lines }\end{array}$ \\
\hline 5 & China's testing ground & $\begin{array}{l}\text { Egypt's Sisi clamped down on political Opposition--next up is the economy; the } \\
\text { military has amassed a growing business empire under the former general-turned- } \\
\text { president, leading to renewed popular resentment }\end{array}$ \\
\hline 6 & Beijing relations raise the emotional heat & $\begin{array}{l}\text { China builds first overseas military outpost; naval facility under construction in } \\
\text { Djibouti shows Beijing's ambitions to be a global maritime power and protect its } \\
\text { expanding interests abroad }\end{array}$ \\
\hline 7 & $\begin{array}{l}\text { Greater Chinese presence built on a } \\
\text { longstanding relationship }\end{array}$ & $\begin{array}{c}\text { Beijing spins a web of Chinese infrastructure; 'New silk road' projects keep the spirit } \\
\text { of globalization alive }\end{array}$ \\
\hline 8 & $\begin{array}{c}\text { Kenyan railway highlights sharper focus on } \\
\text { affordability }\end{array}$ & $\begin{array}{c}\text { China takes wary steps into new Africa deals; premier pledges more business during } \\
\text { trip, but Beijing shows more caution }\end{array}$ \\
\hline 9 & $\begin{array}{l}\text { Beijing denies five-year hack of African union } \\
\text { HQ in Ethiopia }\end{array}$ & $\begin{array}{c}\text { In Africa, those who bet on China face fallout; economic slowdown in China } \\
\text { exacerbates strain for trading partners in Africa }\end{array}$ \\
\hline 10 & $\begin{array}{l}\text { Chinese loans keep Kenya railway project } \\
\text { rolling }\end{array}$ & $\begin{array}{c}\text { Ethiopia set to gain transport lifeline to sea with new } \$ 4 \text { billion railway; project backed } \\
\text { by China will connect Addis Ababa to seaport at Djibouti, aiding Ethiopian } \\
\text { agriculture exporters }\end{array}$ \\
\hline
\end{tabular}

Judging from the above twenty randomly selected headlines, we can see that the Chinese construction enterprises have fulfilled their economic responsibility through helping the African countries build infrastructure. Both news media, however, cover the events mainly from the perspective of China's seeking its own interests, and WSJ links China's assistance to its outward expansion and even claims that China should be responsible for the debt woes of African countries. Apparently the headlines of the coverage of the two media reflect their political stance and this will cause a negative impact on the image of CCEA and even China's national image in Africa and beyond.
4.5. Targeted Keywords Analysis. Adjectives are evaluative in nature, such as good, great, bad, or terrible, and are often used to express the positive or negative effects of a proposition [43], so adjectives are one of the most prominent ways to express the values of different communities [44]. Biber et al. [43, 45] listed three semantic categories of adjectives: emotion, attitude, and evaluation. In addition, other researchers have also studied evaluative adjectives, whose function can be divided into subcategories in a particular language class or discourse community. For example, Hewings [46] analyzed evaluative adjectives, whose propositions can be divided into nine semantic categories, including interest, accuracy, importance, adequacy, 
intelligibility, character, certainty, emotion, and judgment. Nelson [47] classified the adjectives in a business English corpus of 1.5 million words, including size or speed, place, positive, negative, neutral, work or business, currency, technology, and time [48]. Considering this study focuses on the CSR image construction of CCEA which contains emotions, feelings, or attitudes, these previous studies can provide references for the current study. Therefore detailed analysis of the adjectives of the news reports will be made to achieve the aim of the study.

4.5.1. Evaluative Adjectives. There are two types of adjectives and both predicative and attributive adjectives can be included in the analysis of the adjectives for the study; however, only the nouns in the adjective + noun pattern were included for a targeted analysis of the entities immediately adjacent to the evaluative adjectives [48]. So we select the attributive adjectives from the word list generated by AntConc according to their frequencies and then check by concordance to see whether they are used to describe the events related to CCEA. Table 4 shows that the evaluative adjective lists of both media share great similarities in containing such adjectives as new, local, state-owned, big, first, international, overseas, economic, and so forth. Judging from the two lists, it can be seen that both FT and WSJ focus on Chinese state-owned construction enterprises' construction of big projects, Chinese companies' development of new overseas markets, and their bringing commercial benefits to the local people. Thus, we can conclude that Chinese construction enterprises have fulfilled their economic responsibilities in Africa.

Yet there is one detail that should not be ignored. The word military appears 28 times and the other word political appears 20 times in WSJ, respectively. The high frequencies of the two words convey such a message that China aids Africa in constructing infrastructure with an intention of building its military bases to expand its political influence on the continent, which portrays China as a major rival to the US in Africa. In general the coverage of the two media on CCEA concentrates on the economic activities of CCEA, and their reports embed their ideology.

4.5.2. Nouns Modified by Evaluative Adjectives. Entities, such as nouns are often applied to describe the activities of enterprises, so statistics of high-frequency nouns allow readers to learn more about the CSR performance of enterprises. Table 5 lists the top 20 nouns related to the CSR performance of CCEA, which are modified by evaluative adjectives. Judging from the statistical results, we can learn that the coverage of two media is fairly consistent, which is mainly about the business activities of CCEA. It is crystal to see that these companies have performed well in fulfilling their economic social responsibilities by constructing infrastructure, thus benefiting local people as well as the enterprises themselves. Furthermore, the economic activities of CCEA involve the officials of the China and African countries, which suggests that the mutual cooperation is largely driven by the Sino-Africa governments. There are,
TABLE 4: High-frequency evaluative adjectives in the new reports of FT and WSJ.

\begin{tabular}{lcccc}
\hline & FT corpus & Frequency & WSJ corpus & Frequency \\
\hline 1 & new & 34 & new & 38 \\
2 & local & 22 & economic & 34 \\
3 & state-owned & 18 & military & 27 \\
4 & other & 17 & other & 21 \\
5 & big & 16 & political & 20 \\
6 & first & 15 & foreign & 17 \\
7 & international & 15 & first & 12 \\
8 & global & 13 & western & 13 \\
9 & financial & 13 & local & 13 \\
10 & overseas & 13 & many & 12 \\
11 & economic & 12 & private & 12 \\
12 & regional & 12 & electoral & 11 \\
13 & private & 11 & international & 10 \\
14 & huge & 9 & regional & 10 \\
15 & domestic & 8 & state-owned & 9 \\
16 & foreign & 8 & senior & 9 \\
17 & political & 8 & public & 9 \\
18 & western & 8 & former & 8 \\
19 & many & 8 & major & 8 \\
20 & commercial & 7 & big & 8 \\
\hline
\end{tabular}

however, still some differences between the coverage of the two media. When taking a look at the concordance of the word loans, we see that FT propagated the negative impact of Chinese loans with additional conditions on Africa, while WSJ highlighted Chinese and African leaders' efforts to bolster infrastructure building for the benefit of their respective countries and claimed that many of China's projects served oil exploration and military activities when we referred to the concordance of the words power, oil, and officers. On the surface the reports of the two media focus on China's economic activities in Africa, but in fact they overinterpret China's aid to Africa as neocolonialism or resources plunder. In view of the influence of the two media in the UK and the US, such coverage may mislead the African people and even the people from other countries to misjudge Chinese overseas companies as well as China, which is definitely harmful to the overseas activities of Chinese enterprises and even China's diplomatic activities.

4.5.3. Concordance of Low-Frequency Keywords. The statistics of the high-frequency adjectives and nouns reveal the economic social responsibilities of CCEA, but the other social responsibilities are seldom concerned. Feng and Wei [49] pointed out that in 1979 Carroll was the first to summarize the connotation of CSR and constructed a "four-layer pyramid" model, namely, economic responsibility, legal responsibility, ethical responsibility, and discretionary responsibility, which was revised to "economy-law-ethic-charity" in 1991. This model shows that while enterprises are committed to maximizing profits for shareholders, they should also pay attention to laws, regulations, ethics, and morality and vigorously carry out philanthropy. Therefore, concordance is conducted to explore words of low-frequency but closely related to CSR in the specific context so as to further analyze the CSR image of CCEA portrayed by FT and WSJ. 
TABLE 5: High-frequency nouns in the news reports of FT and WSJ.

\begin{tabular}{lcccc}
\hline & FT corpus & Frequency & WSJ corpus & Frequency \\
\hline 1 & power & 22 & capital & 14 \\
2 & projects & 12 & forces & 13 \\
3 & railway & 10 & growth & 12 \\
4 & investment & 10 & infrastructure & 11 \\
5 & companies & 9 & economy & 11 \\
6 & infrastructure & 9 & investment & 9 \\
7 & development & 9 & projects & 8 \\
8 & investments & 9 & countries & 8 \\
9 & countries & 7 & lines & 7 \\
10 & rail & 7 & ties & 7 \\
11 & company & 7 & project & 6 \\
12 & trade & 7 & election & 6 \\
13 & markets & 7 & development & 6 \\
14 & line & 6 & economies & 6 \\
15 & construction & 5 & power & 6 \\
16 & grid & 5 & officers & 6 \\
17 & loans & 5 & oil & 5 \\
18 & state & 5 & port & 5 \\
19 & country & 5 & trade & 5 \\
20 & people & 5 & investors & 5 \\
\hline
\end{tabular}

From the word list generated in the two corpora, the word environmental appears in the coverage of both media, and the word illegal appears in FT reports while the word labor appears in WSJ reports. Abiding by law is the legal responsibility in CSR, while protecting the environment and the rights and interests of employees are the ethical responsibilities of CSR. These two responsibility dimensions are often discussed in CSR as well as economic responsibility. FT covered that the projects aided by China to Africa, such as dam building, had disastrous effects on the local lakes and people's lives (see Figure 3). Some reports even claimed that China did not take environmental protection seriously and some Chinese companies even took their bad habits to Africa. Besides, some African projects which faced difficulties in financing due to environmental concerns had been allowed to proceed with loans from Chinese banks.

The word environmental appears in WSJ only two times less than in FT, but the focus here is not the frequency but the context in which the word is used. Figure 4 indicates that WSJ reports on the environmental protection problems caused by CCEA, among which these companies were forced to sell their shares of some projects after a halt due to the environmental problems and some Chinese companies had caused adverse effects on the local environment because of their ignoring or breaching the local environmental standards.

It is a bit surprising to see only a few reports on the fulfillment of legal responsibilities of CCEA from both media. Yet FT covered that some Chinese companies illegally harvested fish and shellfish and some of them even smuggled ivory and rhino horns across the continent (see Figure 5). These illegal behaviors have obviously damaged the local ecological environment and also violated the laws to protect wildlife, which incurs complaints and protests from the local residents.

Labor disputes are commonly seen in the reports on Chinese enterprises' operations in Africa, which are mainly about local workers' complaints about unfair pay and even striking to defend their legitimate interests. Figure 6 shows that Chinese construction companies often hire Chinese workers to do their projects, which leads to no significant increase of job opportunities for local workers and may have a negative impact on the local economy. In addition, some reports mentioned that some projects were forced to halt due to labor disputes and ended up with share transfer. Unfortunately this coverage did not trace the causes of these problems but simply listed the problems. Apparently, such coverage is unfair to CCEA.

As is discussed in this section, both FT and WSJ focus on the economic responsibility of CCEA, and these reported Chinese construction enterprises are mainly state-owned enterprises, whose activities, as the media claim, are sponsored by the Chinese government, and their activities form a significant part of China's BRI. Moreover it is said that China's massive lending to Africa for infrastructure construction has thrown the continent into a debt trap so that China can get better access to Africa's natural resources in its negotiation with African countries. Besides, the two media released a few reports on the legal and ethical responsibilities of CCEA, but these reports are all negative, and there is no coverage on the charity responsibility. This may contribute to Chinese companies' priority in pursuing economic returns, or indeed Chinese companies' inadequacy in fulfilling other responsibilities or just the deliberate neglect of the two media. No matter what reasons are behind it, the motives of the two media's coverage are worth further discussion.

\subsection{The Motives Behind the Coverage of FT and WSJ.} From the above analyses, it can be seen that the coverage of the two media is greatly consistent, which points to the Chinese construction enterprises' construction of large-scale infrastructure and investments in Africa with the support of Chinese government, but the economic activities of these Chinese companies have caused harm to local environment and residents. A certain ideology is embedded in such coverage, which is detrimental to Chinese companies' overseas operations and even to China's diplomatic activities. To cope with such a challenge, it is crucial for Chinese companies to understand the motives behind such biased coverage so that they can better regulate their own behaviors and fulfill corresponding CSR. The motives behind the coverage of FT and WSJ can be roughly inferred on the basis of the results of the previous analyses.

4.6.1. Motive One. Western countries' rejection of China's subsidies to its state-owned enterprises: in China's national economic system, state-owned enterprises are the mainstay of the country's economic lifeline. These companies are leaders and strong competitors in exploiting overseas markets. In the eyes of the western countries, however, Chinese state-owned construction enterprises have gained an absolute advantage with the support of their government, and that is the reason why western construction companies often lose the contracts in the competition with their 


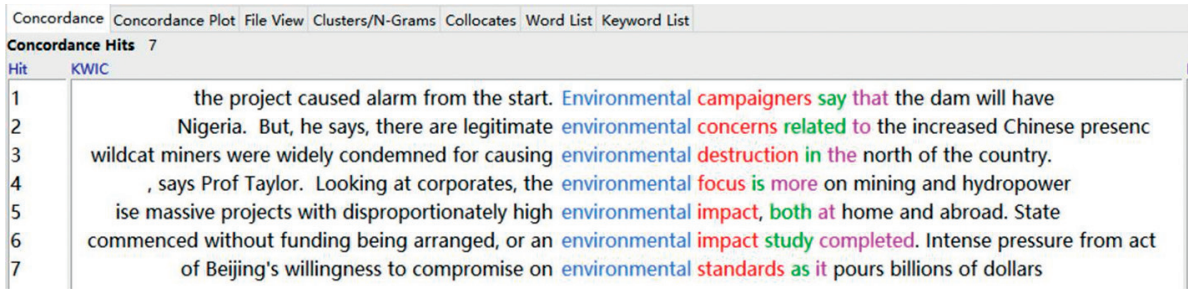

FIgURE 3: Concordance of environmental in the news reports of FT.

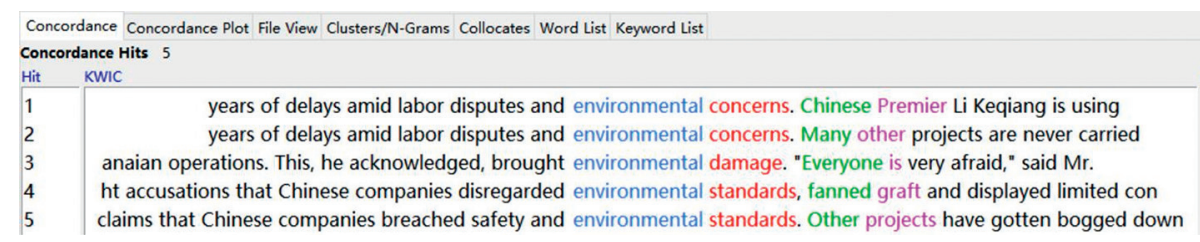

FIGURE 4: Concordance of environmental in the news reports of WSJ.

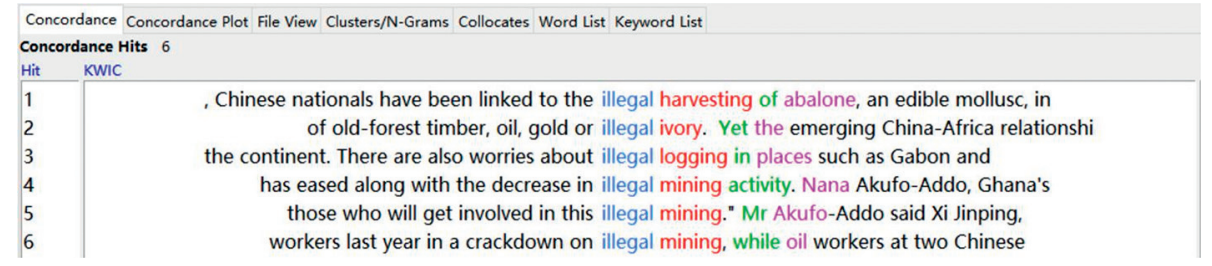

FIgURE 5: Concordance of illegal in the news reports of FT.

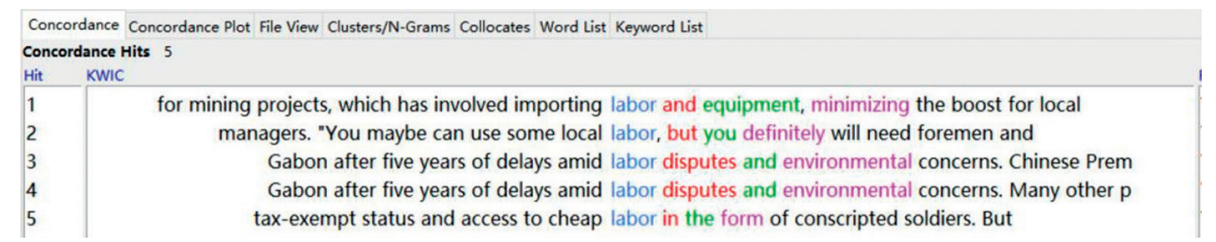

FIgURE 6: Concordance of labor in the news reports of WSJ.

Chinese counterparts in the African market. Admittedly, Chinese state-owned enterprises enjoy a greater competitive advantage in subsidies, credit, government relations, policy support, and so forth. The former deputy secretary of the US, Robert D. Hormats, said that more and more state-owned enterprises and sovereign funds entered the international market after the financial crisis with a competitive edge in the American market and in third countries, but the comparative advantages were provided by their governments instead of their own productivity and innovation. Therefore, he argued that American firms without government support were at a disadvantaged position when competing with these companies $[50,51]$. It should not be ignored, however, that China adopts socialist market economy system, so state-owned enterprises dominate the pillar industries in China's national economy and the Chinese government has launched an increasingly comprehensive and thorough reform of state-owned enterprises since 2012 guided by the core document entitled "Guiding Opinions on Deepening the Reform of State-Owned Enterprises," which was published in 2015, along 22 supplementary files [52].

4.6.2. Motive Two. Western countries' restlessness and unwillingness to see the world center shift from the west to the east: since the reform and opening up, the world has witnessed China's economic miracle. China's desire to become a global economic powerhouse is thus deemed a counterweight to US hegemony in the international system [53]. With China's peaceful rising, it is emerging as a much more active world player. Since the postcrisis era, China has contributed with over $30 \%$ of the world economic growth, making it one of the most dynamic countries in the globe. For example, the promotion of BRI brings more friends to China, yet China's expanding of the African market will 
cause a shock to its western counterparts who have settled in the resource-abundant continent for many years. The interpretation of Africa's renewed geoeconomic position in the global setting leads to a perception that China's growing geopolitical and economic influence in Africa encroaches upon what western powers has seen as its traditional cauldron of interest and influence [54]. So some western countries may interpret China's overseas development as a challenge to the existing international political and economic order lasted for decades. Then, it can be said that "west-centrism" is the root of misjudging China-Africa cooperation [55]. In fact, China has reiterated that it never seeks to challenge the current international order, nor does it seek hegemony.

4.6.3. Motive Three. Western countries' distorting Chinese aid to Africa as neocolonialism: since China began its aid and investment in Africa, its action is interpreted as earlier colonial investments to ensure access to raw materials $[54,56]$. At the present stage of development, Chinese construction enterprises' labor export and outbound investment are a natural outcome of China's economic expansion. China has elevated to the second largest economy and possesses its advantages of low cost but high efficiency in infrastructure construction, coupled with overcapacity in domestic industrial products, such as cement and steel, and at the same time Africa is in urgent need for large-scale infrastructure construction, all of which push Chinese construction enterprises to conduct construction and investments in Africa. With BRI put forward and implemented deeply, however, some western media and politicians are extremely worried about China and desperately vilify and distort the initiative, playing up the so-called "Chinese neocolonialism" fantasy, thus denigrating China-Africa economic cooperation as neocolonialism $[57,58]$.

4.6.4. Motive Four. Western countries' stereotype of bad behaviors of Chinese overseas companies: in the early days of Chinese enterprises' entry to the overseas market, such problems as rampant fake goods, back pay, and environmental damage occurred from time to time due to these companies' limited strength, excessive pursuit of economic benefits, and insufficient understanding of CSR. As a result, an adverse corporate image of Chinese overseas enterprises was highlighted through the overwhelming reports by the western media, which gradually becomes a stereotype of Chinese multinational corporations [59-62]. While Chinese overseas enterprises have been aware of the importance of CSR in recent years, some, especially the small private enterprises which struggle for survival, are still taking chances and conducting illegal activities. Once such adverse events are exposed, the western media will naturally bring up the old story of Chinese companies' misconducts. Even if most of Chinese overseas enterprises have complied with the local laws nowadays, the western media still tend to exaggerate the bad behaviors of a single case.

To sum up, any news media has its own stance, so the coverage of mainstream media often represent the opinions of its sponsors. Once the motives behind the negative coverage of western media are revealed, the CCEA and even other Chinese overseas enterprises can better handle the prejudiced or even unreal reports.

4.7. Suggestions for CCEA to Improve Their CSR Image. In view of the above findings, the following suggestions are proposed to help the CCEA improve their CSR image.

First, establish a comprehensive CSR operation pattern: although enterprises are the main body of fulfilling CSR, it does not mean other stakeholders can be bystanders. For the overseas businesses, CSR image is not only related to their own development but also to the image of their home country, so all the stakeholders, including government, enterprises, and nongovernmental organizations, should be involved in the implementation of CSR. It is noted that in 2014 EthicsSA [3] had conducted a questionnaire survey on Chinese companies' operations in Africa by inquiring 1,056 respondents from 15 Sub-Saharan African countries and the survey results show that only $6 \%$ of respondents from South Africa and $7 \%$ of respondents from Nigeria believed that Chinese companies had considered the interests of the society and the community when making business decisions, and in Kenya $23 \%$ of the respondents shared the same view. This demonstrates a lack of localization of the Chinese enterprises in Africa and their focus is on the communication with African officials and the upper class [63]. Therefore, CCEA should strengthen their dialogue with the local people so as to win more understanding and support when making business decisions.

Second, deepen the understanding of the strategic significance of CSR. Even though Chinese companies are increasingly aware of the importance of fulfilling CSR, many of them still have a shallow understanding on it due to the short history of CSR in China and their excessive emphasis on immediate economic benefits. Wu et al. [26] pointed out that Chinese international contractors' understanding on CSR is distorted and incomplete, which is caused by their insufficient attention to the health and safety management, imperfect professional ethics standards, and neglect of CSR in decision-making and their construction activities. In this regard, it is suggested that China international construction corporations pay more attention to labor conditions, environmental protection, anticorruption, and ameliorate professional ethics so as to establish common values with local enterprises and society. In addition, CCEA should also enhance their understanding of the strategic significance of CSR under the background of China's vigorous promotion of BRI. Carrying out CSR in Africa has received great support from Chinese President Xi Jinping because helping African countries improve their capacity will be beneficial to their self-development, thus advancing a new type of ChinaAfrica strategic partnership and pushing the mutual cooperation [42].

Third, balance the economic responsibility and other social responsibilities. Although economic responsibility comes first, legal, ethical, and philanthropic responsibilities are no less important. CCEA should fulfill the noneconomic 
responsibilities within their power, which is helpful to their long-term interests. According to the survey on "Africans' Perceptions of Chinese Business in Africa" conducted by EthicsSA [3] in 2014, 22.7\% of the respondents gave positive evaluation, while $55.9 \%$ of the respondents offered negative evaluation in respect of the quality of Chinese products and services. As for the feedback on the environmental responsibility of Chinese enterprises in Africa, $53.9 \%$ of the evaluations were negative and only $11.1 \%$ were positive. Besides these disappointing numbers, the CSR performance of the Chinese companies in other aspects was equally unsatisfactory [63]. These figures indicate that there is still much space for Chinese overseas companies to improve their CSR image.

Fourth, create an exclusive communication mechanism. Under the influence of Chinese traditional culture, Chinese enterprises advocate keeping a low profile, thus seldom publicizing what they have done well. Liao et al. [64] conducted a comparative analysis of CSR communication of the selected contractors among Asia, EU, US/Canada, and China and found that European contractors tended to present the highest levels of CSR communication at both dimensional and issue levels, whereas Chinese contractors ranked the lowest. Keeping a low key may work in China, but for companies aiming to operate overseas, it could be the opposite because if a company keeps a low key, it means it gives up the opportunity of making itself known to the public. It is vital for a company to communicate with the outside world when there is negative news about it. Deng and Zhang [65] found that although there is no significant correlation between the quantity of media reports on a company and the public's awareness of it, negative coverage on an enterprise can significantly affect the public's negative perception of it. So publicity is indispensable to transnational corporations. They should disclose CSR information regularly and strengthen the dissemination of CSR activities: for example, releasing English CSR reports annually, enhancing communication with stakeholders, creating CSR websites, and cohosting meetings and forums on CSR with international organizations.

Fifth, strengthen the construction of CSR culture. CSR culture refers to the corporate culture guided by the concept of CSR. It reflects the awareness and sense of CSR and the corporate thinking and behavior norms based on the concept of CSR. Freeman [66] stated that a company is not only owned by the shareholders, but also by many other parties, including employees, customers, suppliers, communities, governments, trade unions, and even competitors. Therefore, an enterprise should consider the responsibilities of stakeholders other than shareholders while pursuing profits, seeking the coordinated development of the interests of the enterprise and stakeholders [24]. CSR culture plays a key role in promoting enterprises to discretionarily fulfill their social responsibilities and its function is more effective and more lasting than the mandatory role of law. To construct CSR culture is to internalize the CSR consciousness into the enterprises as a value, thus forming their inner impetus. It includes two tasks: one is to transform CSR into the consciousness and action of employees through the normative function of culture and the other is to influence external stakeholders to accept CSR culture through the radiation and cohesion of the culture.

\section{Conclusion}

This study finds that both FT and WSJ focus on the economic responsibilities of CCEA, with much less attention on the other social responsibilities. The overall CSR image of CCEA portrayed by the two media is that Chinese state-owned construction enterprises have conducted large-scale infrastructure construction and investments in Africa, which not only wins economic benefits for Chinese companies but also promotes the economic development of Africa. However, the CCEA are mainly state-owned enterprises, and their business activities reflect the will of their home country, thus constituting an important part of China's BRI. These activities are interpreted as significant measures of China to expand its influence in Africa. Both media, especially WSJ, pointed out that China had provided a large number of loans for African countries, and this behavior has thrown African countries into debt traps so that China is able to gain the upper hand in its negotiations with African countries for more natural resources. Moreover, the two media also reported the misconducts, like environmental damage and labor disputes, of the Chinese construction enterprises. In general both FT and WSJ portray a negative CSR image of CCEA, which coincides with such speech as "neocolonialists," "resource predators," and "ecological disruptors" prevalent in the west.

The main motives behind the biased coverage of the two media are related to their political stance, ideology, and their stereotype of the early misconducts of Chinese overseas enterprises. The Chinese companies involved in African infrastructure construction are mainly state-owned enterprises, so the western media often misinterpret the competitive advantages of these companies as China's improper subsidies to them. Moreover, China's promotion of BRI brings vast opportunities to Chinese enterprises as well as the companies of those countries which have joined the initiative. Unfortunately, this proposal is distorted by the western media as China's colonization of Africa and such misinterpretation is not only prevalent in the west, but also stirs up concerns in Africa. Besides, western media's rigid impression of the early inappropriate behaviors of Chinese overseas enterprises, like labor disputes and environmental destruction, also leads to their prejudiced coverage.

Even though the coverage of the two media contains subjective elements, it also provides a warning for CCEA to reflect on their business behaviors in the international markets. This study thus puts forward some suggestions for CCEA to perfect their CSR image, which involve comprehensive participation of stakeholders in CSR construction, better understanding of CSR, balance of four levels of CSR, and so forth. These proposals are also applicable to other Chinese overseas companies.

The present study innovates the research methods in exploring CSR image of enterprises by utilizing data mining 
and corpus analysis from an interdisciplinary perspective, namely, an integration of data science, communications, management, and linguistics. However, it also has its own limitations. Only two media are included and the quantity of news samples are confined to thirty-three, which may affect the generalization of the results. Therefore, the future study is recommended to cover more media to increase the quantity of samples and a comparison of the coverage of African media and Chinese media is also worth trying.

\section{Data Availability}

The original report data of Financial Times and The Wall Street Journal are obtained from the ProQuest ABI/INFORM business information database which was released by ProQuest. Guangdong University of Foreign Studies, where the authors study or work, has purchased this database as part of the resources of its school library. The data related to statistics of word frequency and concordance of key words used to support the findings of this study are included within the article. The complete key word list generated by NVivo and the complete word lists generated by AntConc used to support the findings of this study are available from the corresponding author upon request.

\section{Conflicts of Interest}

The authors declare that there are no conflicts of interest regarding the publication of this paper.

\section{Acknowledgments}

This work was supported by the 2019 Project of the National Social Science Foundation of China: On the Overseas CSR Driving Forces and Influencing Mechanism for Chinese Enterprises (19BGL116).

\section{References}

[1] "List of countries that have signed the Belt and Road Initiative cooperation document with China," 2020, https://www. yidaiyilu.gov.cn/xwzx/roll/77298.htm.

[2] A. P. Zeng, "The status quo, challenges and countermeasures of China's investment and financing in Africa," 2020, https://baijiahao. baidu.com/s?id= 16372013810737988869\&wfr=spider\&for=pc.

[3] S. Geerts, N. Xinwa, and D. Rossouw, Africans' Perceptions of Chinese Business in Africa, Geneva: Globethics.net/Hatfield: Ethics Institute of South Africa, Ethics Institute of South Africa, Hatfield, Pretoria South Africa, 2014.

[4] M. J. Kim, X. M. Yin, and G. M. Lee, "The effect of CSR on corporate image, customer citizenship behaviors, and customers' long-term relationship orientation," International Journal of Hospitality Management, vol. 88, Article ID 102520, 8 pages, 2020.

[5] P. C. Tang, S. X. Yang, and S. W. Yang, "How to design corporate governance structures to enhance corporate social responsibility in China's mining state-owned enterprises?," Resources Policy, vol. 66, Article ID 101619, 11 pages, 2020.

[6] P. S. Hofman, J. Moon, and B. Wu, "Corporate social responsibility under authoritarian capitalism: dynamics and prospects of state-led and society-driven CSR," Business \& Society, vol. 56, no. 5, pp. 651-671, 2017.
[7] Q. Zhang, B. L. Oo, and B. T. H. Lim, "Drivers, motivations, and barriers to the implementation of corporate social responsibility practices by construction enterprises: A review," Journal of Cleaner Production, vol. 210, pp. 563-584, 2019.

[8] Z. Chen and T. Hamilton, "What is driving corporate social and environmental responsibility in China? An evaluation of legacy effects, organizational characteristics, and transnational pressures," Geoforum, vol. 110, pp. 116-124, 2020.

[9] B. Xiong, W. Lu, M. Skitmore, K. W. Chau, and M. Ye, "Virtuous nexus between corporate social performance and financial performance: a study of construction enterprises in China," Journal of Cleaner Production, vol. 129, pp. 223-233, 2016.

[10] Q. Zhu, J. Liu, and K.-H. Lai, “Corporate social responsibility practices and performance improvement among Chinese national state-owned enterprises," International Journal of Production Economics, vol. 171, pp. 417-426, 2016.

[11] J.-M. Byun and J. M. Oh, "Local corporate social responsibility, media coverage, and shareholder value," Journal of Banking \& Finance, vol. 87, pp. 68-86, 2018.

[12] Y. Zhang and M. Cui, "The impact of corporate social responsibility on the enterprise value of China's listed coal enterprises," The Extractive Industries and Society, vol. 7, no. 1, pp. 138-145, 2020.

[13] F. Li and T. Morris, "An analysis of the impact of corporate visibility in print media and its effects on corporate social responsibility," International Journal of Global Business, vol. 11, no. 1, pp. 39-66, 2018.

[14] S. F. Cahan, C. Chen, L. Chen, and N. H. Nguyen, "Corporate social responsibility and media coverage," Journal of Banking \& Finance, vol. 59, pp. 409-422, 2015.

[15] X. Du, H. Pei, Y. Du, and Q. Zeng, "Media coverage, family ownership, and corporate philanthropic giving: evidence from China," Journal of Management \& Organization, vol. 22, no. 2, pp. 224-253, 2016.

[16] B. Xia, A. Olanipekun, Q. Chen, L. Xie, and Y. Liu, "Conceptualising the state of the art of corporate social responsibility (CSR) in the construction industry and its nexus to sustainable development," Journal of Cleaner Production, vol. 195, pp. 340-353, 2018.

[17] W. Jiang and J. K. W. Wong, "Key activity areas of corporate social responsibility (CSR) in the construction industry: a study of China," Journal of Cleaner Production, vol. 113, pp. 850-860, 2016.

[18] Z.-Y. Zhao, X.-J. Zhao, K. Davidson, and J. Zuo, “A corporate social responsibility indicator system for construction enterprises," Journal of Cleaner Production, vol. 29-30, no. 29-30, pp. 277-289, 2012.

[19] H. R. Bowen, Social Responsibilities of the Businessman, Harper \& Row, New York, NY, USA, 1953.

[20] A. B. Carroll, "A three-dimensional conceptual model of corporate performance," Academy of Management Review, vol. 4, no. 4, pp. 497-505, 1979.

[21] A. B. Carroll, "The pyramid of corporate social responsibility: toward the moral management of organizational stakeholders," Business Horizons, vol. 34, no. 4, pp. 39-48, 1991.

[22] A. Dahlsrud, "How corporate social responsibility is defined: an analysis of 37 definitions," Corporate Social Responsibility and Environmental Management, vol. 15, no. 1, pp. 1-13, 2008.

[23] C. Y. An, "China's CSR in Africa: a case study of ZambiaChina economic and trade cooperation zone," Asia \& Africa Review, vol. 2, pp. 92-130, 2014. 
[24] Z. F. Liu, Corporate Social Responsibility and Corporate Image Building, China Financial \& Economic Publishing House, Beijing, China, 2008.

[25] B. R. Yang, "Summary of international symposium on corporate social responsibility and development in africa," West Asia and Africa, vol. 8, pp. 73-75, 2010.

[26] C.-L. Wu, D.-P. Fang, P.-C. Liao, J.-W. Xue, Y. Li, and T. Wang, "Perception of corporate social responsibility: the case of Chinese international contractors," Journal of Cleaner Production, vol. 107, pp. 185-194, 2015.

[27] N. Nguyen and G. Leblanc, "Corporate image and corporate reputation in customers' retention decisions in services," Journal of Retailing and Consumer Services, vol. 8, no. 4, pp. 227-236, 2001.

[28] G. B. Song, Study on CSR Building of Chinese Enterprises in Africa, Shanghai, Shanghai Institutes for International Studies, Shanghai, China, 2012.

[29] J. Fang, "Some considerations about Chinese enterprises' social responsibility in Africa," Petroleum \& Petrochemical Today, vol. 26, no. 10, pp. 42-47, 2018.

[30] Q. M. Guo, "On image of China and China's MNCs in Africa," China Opening Journal, vol. 4, pp. 37-40, 2012.

[31] X. H. Chen, T. Jia, and Y. Zhou, "Chinese corporate social responsibility in Africa: present state and proposals," China Development Review, vol. 12, no. 1, pp. 75-83, 2010.

[32] X. S. Han, "The development of Chinese enterprises in Africa and their social responsibilities," Journal of International Economic Cooperation, vol. 7, pp. 18-20, 2007.

[33] J. C. Shu, "Small and medium sized enterprises' CSR in Africa: status quo and some recommendations," Asia \& Africa Review, vol. 5, pp. 54-62, 2011.

[34] H. W. Zhong and X. K. Yang, "Social responsibility: a problem that Chinese overseas companies must handle," China WTO Tribune, vol. 8, pp. 50-52, 2007.

[35] X. L. Wang, "A study on the social responsibility of Chinese enterprises in Africa - A case study of the Mombasa-Nairobi Railway," Economic Forum, vol. 12, pp. 139-141, 2016.

[36] S. M. Zhan, "Fulfilling corporate social responsibility promotes the common development of China and Africa-investigation report on 'Chinese enterprises fulfilling social responsibilities in Africa'," West Asia and Africa, vol. 7, pp. 63-66, 2008.

[37] J. Feng, "Chinese contractor involvement in wildlife protection in Africa: case study of mombasa-nairobi standard Gauge railway project, Kenya," Land Use Policy, vol. 95, Article ID 104650, 7 pages, 2020.

[38] Y. X. Tan and C. C. Hua, "Analysis of cluster on the inversion problem of network public opinion events," Journal of Yunnan University, vol. 41, no. S1, pp. 16-20, 2019.

[39] L. H. Liu, Research on National, Regional and Corporate Communication: A Perspective of Discourse Analysis, People Daily Press, Beijing, China, 2016.

[40] Wikipedia, "Financial Times," 2020, https://en.m.wikipedia. org/wiki/Financial_Times.

[41] Wikipedia, “The Wall Street Journal," 2020, https://en.m. wikipedia.org/wiki/The_Wall_Street_Journal.

[42] G. F. Yin, Y. Wang, Z. S. Guan et al., "The development course and characteristics of CSR in Africa," China WTO Tribune, vol. 11, pp. 17-26, 2016.

[43] D. Biber and University language, A Corpus-Based Study of Spoken and Written Registers, John Benjamins, Amsterdam \& Philadelphia, 2006.
[44] M. J. Luzon, "Your argument is wrong': a contribution to the study of evaluation in academic weblogs," Text \& Talk, vol. 32, no. 2, pp. 145-165, 2012.

[45] D. Biber, "Stance in spoken and written university registers," Journal of English for Academic Purposes, vol. 5, no. 2, pp. 97-116, 2006b.

[46] M. Hewings, "An important contribution? or tiresome reading? A study of evaluation in peer reviews of journal article submissions," Journal of Applied Linguistics, vol. 1, no. 3, pp. 247-274, 2004.

[47] M. Nelson, "A corpus-based study of the lexis of business english and business English teaching materials," Unpublished thesis, University of Manchester, Manchester, England, UK, 2000.

[48] R. Poole, "New opportunities and Strong performance: evaluative adjectives in letters to shareholders and potential for pedagogically-downsized specialized corpora," English for Specific Purposes, vol. 47, pp. 40-51, 2017.

[49] M. Feng and J. Wei, An Introduction to Corporate Social Responsibility, Economic Science Press, Beijing, China, 2017.

[50] G. R. Hu, "The influence of competitive neutrality on stateowned enterprises in China and the legal response," Science of Law, vol. 6, pp. 165-172, 2014.

[51] L. Q. Bu, "Competitive neutrality and preliminary discussion on Chinese state-owned enterprise reform," Economic Law Forum, no. 2, pp. 95-121, 2017.

[52] K. J. Lin, X. Lu, J. Zhang, and Y. Zheng, "State-owned enterprises in China: a review of 40 years of research and practice," China Journal of Accounting Research, vol. 13, no. 1, pp. 31-55, 2020.

[53] P. R. Carmody and F. Y. Owusu, "Competing hegemons? Chinese versus American geo-economic strategies in Africa," Political Geography, vol. 26, no. 5, pp. 504-524, 2007.

[54] S. Naidu and D. Mbazima, "China-African relations: a new impulse in a changing continental landscape," Futures, vol. 40, no. 8, pp. 748-761, 2008.

[55] W. Zhou and F. Zhao, "Is China-Africa cooperation under the belt and road initiative neo-colonialism?" Studies on Marxism, vol. 1, pp. 129-152.

[56] H. Z. Ma and E. F. Cheng, "An analysis of 'new neocolonialism' in China-Africa economic and trade relations," Shanghai Journal of Economics, vol. 4, pp. 96-106, 2018.

[57] M. X. Sun, “The predicament of China's national image construction and and breakthrough," Journal of the Central Institute of Socialism, vol. 4, pp. 64-70, 2018.

[58] X. L. Han, "Reflections on Chinese economic engagement in Africa from the perspective of international law-Refuting western slander of neocolonialism through grafting and transplanting," Journal of International Economic Law, vol. 2, pp. 31-48, 2019.

[59] C. Peng, A Study of the News Coverage on Chinese PrivatelyOwned Multinational Enterprises in the Main Stream Media of the USA and UK, Shanghai International Studies University, Shanghai, China, 2014.

[60] C. X. Li, 'Image of Made in China' Constructed by American Media and Solution to the Risk, Fudan University, Shanghai, China, 2010.

[61] J. Yan and J. Y. Shi, "Image of 'Made in China' depicted by western media-An content analysis of the Wall Street Journal in 2007 and 2008," Henan Social Sciences, vol. 18, no. 1, pp. 183-186, 2010.

[62] X. L. Wang and G. Han, “'Made in China' and national image: a content analysis of 30 years' coverage in American 
mainstream media," Chinese Journal of International Communication, no. 9, pp. 49-55, 2010.

[63] P. F. Li, "Reputational risk of Chinese companies in Africa," Sino Foreign Management, vol. 9, p. 31, 2014.

[64] P.-C. Liao, N.-N. Xia, C.-L. Wu, X.-L. Zhang, and J.-L. Yeh, "Communicating the corporate social responsibility (CSR) of international contractors: content analysis of CSR reporting," Journal of Cleaner Production, vol. 156, pp. 327-336, 2017.

[65] L. F. Deng and N. Zhang, "Agenda-setting effects of business news on corporate reputation: research on the news of corporate social responsibility in China," Modern Communication, vol. 5, pp. 119-125, 2013.

[66] R. E. Freeman, Strategic Management: A Stakeholder Approach, Pitman, Boston, MA, USA, 1984. 